\title{
The Energetic Performance of Vehicles
}

\author{
J.L. Radtke*
}

Neodymics, Madison, Wisconsin, USA

\begin{abstract}
Various methods of determining the energetic performance of vehicles were described and compared. Earlier work emphasized maximum vehicle power and theoretical performance limits, and characterized the vehicle or payload in terms of weight. Energetic efficiency was calculated here as the payload mass times distance moved divided by thermal energy used. This efficiency was multiplied by average speed to yield an energetic performance parameter that was expressed in seconds, using SI units. The differential form of this parameter was twice the useful payload kinetic energy divided by thermal power expenditure. A transportation matrix was developed, describing how vehicles are most commonly used in terms of speed, efficiency, GHG emissions, payload mass and energetic performance. Vehicles with the highest level of energetic performance have efficient powerplants, high payload to gross mass ratios, or reduced friction with the surrounding environment.
\end{abstract}

Keywords: Energetic performance, Gabrielli-von Karman limit, vehicle efficiency, vehicle performance.

\section{INTRODUCTION}

In evaluating transportation choices, efficiency is an important and well-characterized consideration. Average speed is also important, since people are paid by the hour and "time is money." Others have considered this interplay between vehicle speed and efficiency.

Gabrielli and von Karman [1] defined the specific resistance of a vehicle, $\boldsymbol{\varepsilon}$, as maximum motor output power $P$, divided by total vehicle weight $W$ multiplied by maximum speed $V_{M}$.

$\varepsilon=P / W V_{M}$

Specific resistance was determined for various vehicles operating at a range of speeds. An empirical limit for the minimum specific resistance as a function of maximum speed was found for any isolated vehicle. This was described by Eq. 2, where $A$ is 0.000175 hours per mile. This relationship is depicted by the diagonal line in Fig. (1), which has become known as the Gabrielli-von Karman limit line of vehicular performance.

$(\varepsilon)_{\min }=A V_{M}$

Gabrielli and von Karman [1] used gross vehicle rather than payload weight because, "exact information regarding the useful load of vehicles was not available to the authors." Their analysis was reconsidered, with regard to payload weight and fuel consumption, by Stamper [2]. This latter treatment was more relevant to the economical application of energy resources. Here, "useful transport work" was defined as the product of payload weight and distance traveled. "Transport efficiency" was defined as the ratio of useful transport work to thermal energy expended.

*Address correspondence to this author at the Neodymics, P.O. Box 55252, Madison, WI 53705, USA; E-mail: jr@neodymics.com
In a subsequent analysis by Teitler and Proodan [3], a quantity was defined as the specific fuel expenditure $\boldsymbol{\varepsilon}_{F}$, where $\zeta$ is the energy per unit volume of fuel, $\boldsymbol{\eta}$ is the distance traveled per unit volume of fuel, and $W_{P}$ is the weight of the vehicle payload.

$\varepsilon_{F}=\zeta / \eta W_{P}$

The reciprocal of $\boldsymbol{\varepsilon}_{F}$ was defined as the fuel transport effectiveness, and related to vehicle cruising speed $V_{C}$ by Eq. 4. Following Stamper's definition, the reciprocal of $\boldsymbol{\varepsilon}_{F}$ was referred to as, "the dimensionless ratio of useful work output to energy input." $C_{F}$ was referred to as a "factor of proportionality." As shown in Fig. (2), $C_{F}$ was applied as a limit to what is technologically possible, rather than as a performance parameter to be applied generally to individual vehicles. The dashed diagonal line was referred to as, "the next level of fuel transport effectiveness to be used as a future standard."

$\left(\varepsilon_{F}^{-1}\right)_{\max }=C_{F}^{-1} V_{C}^{-1}$

Other writers referencing Gabrielli and von Karman [1] have also applied $A$ or $C_{F}$ as a factor describing an experiential performance limit, while treating $\boldsymbol{\varepsilon}_{F}{ }^{-1}$ or $\boldsymbol{\varepsilon}_{F}$ as a general performance parameter. These include Greenwalt [4], Carson [5], Minetti et al. [6], Young et al. [7].

There is another vehicle performance parameter that is expressed in units of time or velocity. As described by Sutton [8], specific impulse, $I_{S}$, is a universally accepted parameter used to describe rocket motor performance. It is defined as shown in Eq. 5, where $F$ is the motor thrust force, $m$ dot is the propellant mass flow rate, and $w$ dot is the propellant weight flow under constant thrust conditions.

$I_{s}=F /\left(\dot{m} g_{o}\right)=F / \dot{w}$

Force divided by propellant mass flow is also used to describe rocket motor performance. This is known as the 


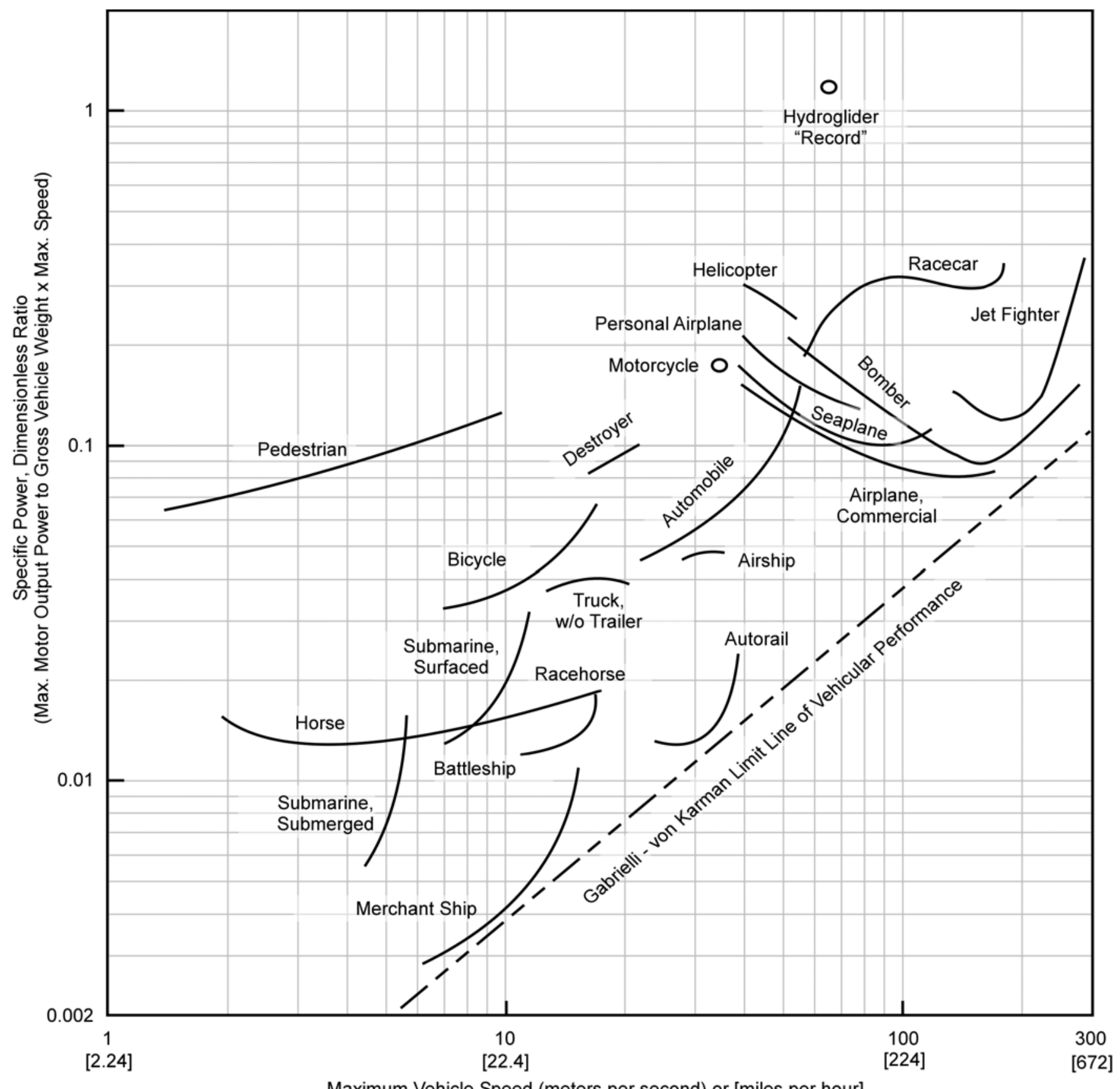

Maximum Vehicle Speed (meters per second) or [miles per hour]

Fig. (1). Specific resistance of single vehicles available in 1950. Diagonal is G-K limit line of vehicular performance. Adapted from Gabrielli and von Karman [1].

effective exhaust velocity, and has units of speed. Ascribing mass to propellant gives a physical insight into this performance parameter; it is proportional to rocket motor exhaust velocity (Sutton [8]).

\section{Analysis}

In combining speed and energy expenditure to yield an energetic performance parameter, $\boldsymbol{\varepsilon}_{F}$ is more economically informative than $\boldsymbol{\varepsilon}$. The specific fuel expenditure $\boldsymbol{\varepsilon}_{F}$ takes payload weight and motor efficiency into account under cruising conditions, and is more representative of actual use and indicative of resultant benefit. $C_{F}{ }^{-1}$ is convenient be- cause an increase corresponds to a performance improvement.

Defining useful transport work as the product of travel distance and payload weight is misleading, since mechanical work is conventionally defined by the vector dot product of force and spatial displacement. For horizontal displacement near the earth's surface, payload weight is a force perpendicular to the direction of motion, so that the work done in this fashion is zero. The dot product of the payload weight and distance traveled is vertical displacement multiplied by the force exerted by the payload mass. This dot product divided by thermal energy expenditure is a true measure of lifting efficiency, and is always less than unity. 


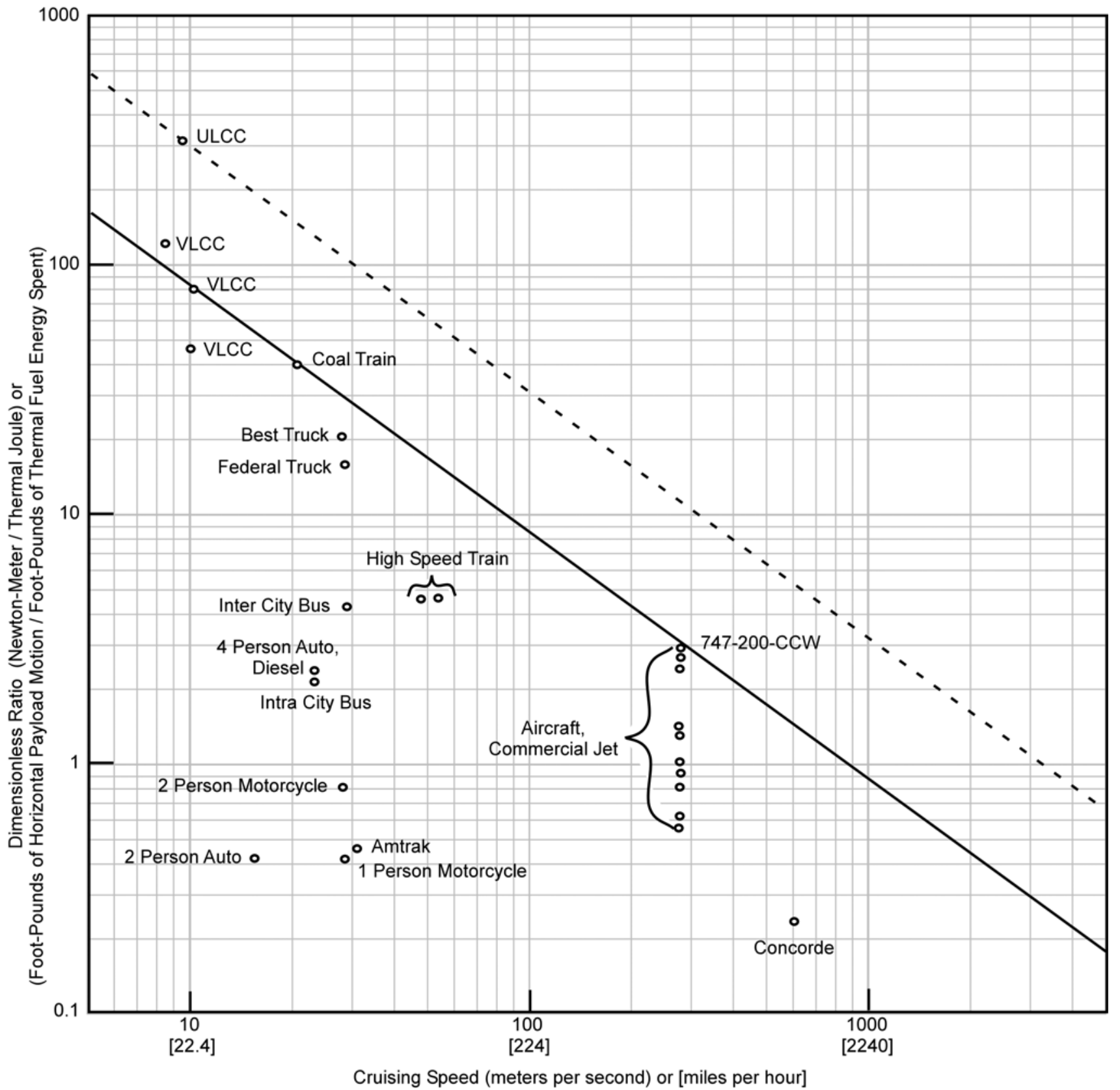

Fig. (2). Dimensionless fuel transport effectiveness $\left(\boldsymbol{\varepsilon}_{F}^{-1}\right)$ plotted as a function of cruising speed for various vehicles available in 1980. Extension of G-K limit is indicated by dashed line. Adapted from Teitler and Proodian [3].

Treating the payload as a mass (denoted $M_{P}$ ) rather than a weight yields a performance parameter $Q$ with units of time. For cruising conditions, $Q_{C}$ is defined by Eq. 6, where $g_{o}$ is the acceleration due to gravity.

An analogous fuel transport effectiveness is defined by Eq. 7, with $E_{t h}$ representing the thermal energy expended to travel a path length, denoted as $l$. The parameter $\boldsymbol{\varepsilon}_{Q}{ }^{-1}$ is also referred to as the thermal transportation efficiency, and it has been used by others to compare various modes of transport (e.g., Hobson [9]).

$$
\begin{aligned}
& Q_{C}=g_{o} / C_{F}=V_{C} M_{P} \eta / \zeta \\
& \varepsilon_{Q}^{-1}=Q_{C} / V_{C}=\left[l M_{P} / E_{t h}\right]_{C}
\end{aligned}
$$

As shown in Eq. 8, the differential form of the travel distance to thermal energy ratio becomes the ratio of cruising speed to thermal power expenditure $\left(P_{t h}\right)$. Eq. 9 thus provides a physical interpretation of $Q_{C}$ as the time during which a total fuel energy release equals twice the payload kinetic energy $\left(E_{k}\right)$.

$$
\begin{aligned}
& \eta / \zeta=\left[l / E_{t h}\right]_{C}=\left[V / P_{t h}\right]_{C} \\
& Q_{C}=\left[M_{p} V^{2} / P_{t h}\right]_{C}=2\left[E_{k} / P_{t h}\right]_{C}
\end{aligned}
$$

Propellant weight is the quantity a rocket designer would like to minimize while obtaining the same result. Since fuel (energy) consumption is the quantity most other vehicle designers endeavor to minimize, and $Q_{C}$ is an energy divided 
by an energy flow, $Q_{C}$ is analogous to $I_{S}$. Ascribing mass rather than weight to matter provides a physical insight into both vehicle performance parameters.

Using mass rather than weight to describe energetic performance yields a result which can be consistently applied in any environment, as illustrated by considering an extraterrestrial vehicle. Due to differences in gravitational acceleration and atmospheric density, a vehicle should travel further on Mars (for example) than on earth, using the same quantity of energy. Defining performance with $C_{F}{ }^{-1}$ gives a result that decreases because of the atmospheric density difference, and does not change because of the difference in gravitational acceleration. On the other hand, $Q_{C}$ increases due to both influences, and is more indicative of the change in conditions. Whether moving a payload mass through a gravitational field or head wind, $Q$ consistently reflects changes in conditions. A pedagogically inferior treatment of this discrepancy is to introduce the concept of "standard weight," which is a measure of mass expressed in units of weight.

Transportation modes are often compared in terms of fuel economy, or distance traveled per unit volume of fuel, and $Q_{C}$ can be defined as a related quantity. $Q_{C}$ can readily be determined from vehicle speed, and automobile person-miles per gallon of gasoline or freight carrier british thermal units per ton-mile. Given that a gallon of gasoline contains about 133 megajoules of thermal energy (Hobson [9]), one can readily determine $Q_{C}$ for a given number of persons in an automobile from the cruising fuel economy rating. Cruise conditions are similar to those encountered on a long distance highway trip, and it is tempting to use the automobile "highway" miles per gallon rating to determine $l / E_{t h}$.

The EPA fuel economy ratings are intended to represent how vehicles are actually used. The highway rating is meant to model free flow traffic at highway speeds. This is measured with a dynamometer system over a simulated distance of only ten miles, with no stops and a maximum speed of 60 miles per hour $(27 \mathrm{~m} / \mathrm{s})$. Average speed during test is 48 miles per hour $(21 \mathrm{~m} / \mathrm{s})$. City driving conditions are simulated over a distance of 11 miles $(18 \mathrm{~km})$, with 23 stops and a maximum speed of 56 miles per hour $(25 \mathrm{~m} / \mathrm{s})$. Average speed during city driving simulation is only 20 miles per hour $(8.9 \mathrm{~m} / \mathrm{s})$. Fuel consumption is measured over these short simulated distances by collecting and analyzing exhaust gas [10].

By using the EPA fuel economy ratings $\left[l / E_{t h}\right]_{E}$, measured at an average speed, $V_{E}$, we can calculate an effective energetic performance, $Q_{E}$, for transporting given number of persons through the EPA driving routine. This is shown in Eq. 10 below. Since the mass of the human payload is typically much less than the mass of the car, it is assumed that $\left[l / E_{t h}\right]_{E}$ does not change based on how many persons are in the automobile.

$Q_{E}=M_{P} l V_{E} / E_{t h}=M_{P} V_{E}^{2} / P_{t h}$

As described in the appendix, the physical meaning of $Q$ changes when average speed is substituted for steady state cruising speed. The numerator in Eq. 9 becomes twice the effective useful payload kinetic energy, which is evaluated at the average speed. This differs from the average payload kinetic energy, which is determined from the root mean square (rms) velocity. Because rms velocity is always greater than or equal to average speed, the payload kinetic energy evaluated at the average speed is the minimum possible average kinetic energy for any velocity profile. It may be difficult to obtain rms velocities, and these higher values would not represent an improvement in the utility of the trip. A vehicle traveling at constant velocity on an elevated express lane is assumed to be no more or less useful than a vehicle traveling at the same average speed through a series of stops. To use rms speed would inflate the value of $Q_{E}$ in the latter case. The denominator in Eq. 9 is still the average thermal power expenditure, which is measured directly. Using the average speed to determine performance thus takes the effectiveness of the velocity profile into account. The parameter $Q_{E}$ is applicable to intermodal comparisons of transportation energy use.

For some modes of mass transit, a passenger may spend a considerable amount of time captive within the system, perhaps while not even being present on the vehicle or while the vehicle itself waits for other vehicles. This describes air travel in particular. For this situation, $V_{E}$ is determined by dividing the distance between airports by the average time between passengers entering the departure airport and leaving the arrival airport.

Table 1 gives efficiency, greenhouse gas emissions, payload mass, speed and energetic performance for various modes of human transportation. Efficiency is determined by estimating the number of payload kilogram-kilometers obtained per Joule of thermal energy present in the fuel consumed. Typical human mass is assumed to be 70 kilograms. The human body is assumed to be $25 \%$ efficient in converting the caloric content of food into mechanical work (DeLong [11]). Moped vehicles are assumed to be ridden without pedaling. Since carbon dioxide emission is directly proportional to energy consumption, this column was easily added. It has been estimated that 10.7 kilograms of $\mathrm{CO}_{2}$ is emitted per gallon (3.78 liter) of gasoline burned (Google [12]). Emissions associated with the use of electrical energy were determined for electricity obtained in 2007 Denver, with its assortment of generation facilities, load factors and distribution patterns. In an analysis published by the City of Denver [13] it was estimated that 0.796 kilograms of $\mathrm{CO}_{2}$ is emitted per kilowatt-hour of electricity delivered. Table $\mathbf{1}$ was sorted first by payload mass, then by energetic performance. This indicates a trend for personal vehicles traveling at low speeds, where vehicles with highest payload to vehicle mass ratios tend to perform better. At higher speeds, aerodynamic effects predominate. Fig. (3) is a logarithmic representation of the data from Table $\mathbf{1}$.

The most complex efficiency determinations were those of electric vehicles. Since electrical energy is a more organized form than thermal energy, it is important to determine how much thermal energy was expended in creating the electricity used to charge the vehicle batteries. By measuring 
Table 1. Thermal Efficiency and Energetic Performance of Various Transportation Modes

\begin{tabular}{|c|c|c|c|c|c|c|c|c|c|}
\hline \multirow{2}{*}{ Mode } & Fuel Econ. & Emissive Eff. & Payload Mass & \multirow{2}{*}{$1 / \varepsilon_{F}$} & $1 / \varepsilon_{Q}$ & Speed & Speed & $\mathbf{Q}$ & \multirow{2}{*}{ Form } \\
\hline & (Person-MPG) & $(\mathrm{kg}-\mathrm{km} / \mathrm{gCO} 2 \mathrm{e})$ & (kg) & & $(\mathrm{kg}-\mathrm{m} / \mathrm{Jth})$ & $(\mathbf{M i} / \mathbf{H r})$ & $(\mathbf{m} / \mathbf{s})$ & (s) & \\
\hline Bicycle, Faired & 1149.0 & & 70 & 9.54 & $0.973^{\mathrm{a}}$ & $75.0^{\mathrm{a}}$ & 33.5 & 32.62 & $\mathrm{Q}_{\mathrm{E}}$ \\
\hline Bicycle, Racing & 1231.6 & & 70 & 10.23 & $1.043^{\mathrm{b}}$ & $20.0^{\mathrm{b}}$ & 8.9 & 9.32 & $\mathrm{Q}_{\mathrm{E}}$ \\
\hline Bicycle, Touring & 1967.3 & & 70 & 16.34 & $1.666^{\mathrm{b}}$ & $12.0^{\mathrm{b}}$ & 5.4 & 8.94 & $\mathrm{Q}_{\mathrm{E}}$ \\
\hline Motorcycle, Completely Faired & $470.0^{\mathrm{c}}$ & 4.93 & 70 & 3.90 & 0.398 & $50.1^{\mathrm{c}}$ & 22.4 & 8.91 & $\mathrm{Q}_{\mathrm{E}}$ \\
\hline Bicycle, Touring & 1215.2 & 12.76 & 70 & 10.09 & $1.029^{\mathrm{b}}$ & $17.0^{\mathrm{b}}$ & 7.6 & 7.82 & $\mathrm{Q}_{\mathrm{E}}$ \\
\hline Bicycle, Touring & 818.3 & & 70 & 6.80 & $0.693^{\mathrm{b}}$ & $20.0^{\mathrm{b}}$ & 8.9 & 6.20 & $\mathrm{Q}_{\mathrm{E}}$ \\
\hline Bicycle, Electric Cyclemotor & 715.6 & 7.51 & 70 & 5.94 & 0.606 & 17.0 & 7.6 & 4.60 & $\mathrm{Q}_{\mathrm{E}}$ \\
\hline Bicycle, Electric Cyclemotor & 357.9 & 4.33 & 70 & 2.97 & 0.303 & 25.0 & 11.2 & 3.39 & $\mathrm{Q}_{\mathrm{E}}$ \\
\hline Airplane, 1 Person N99VE & $50.8^{\mathrm{d}}$ & 0.53 & 70 & 0.42 & 0.043 & $169.5^{\mathrm{d}}$ & 75.8 & 3.26 & $\mathrm{Q}_{\mathrm{E}}$ \\
\hline Elec Trike, Twike & 90.9 & 1.10 & 70 & 0.76 & $0.077^{\mathrm{e}}$ & 53.0 & $23.7^{\mathrm{e}}$ & 1.82 & $\mathrm{Q}_{\mathrm{C}}$ \\
\hline Motorcycle & 48.4 & 0.51 & 70 & $0.40^{\mathrm{f}}$ & 0.041 & 55.0 & $24.6^{\mathrm{f}}$ & 1.01 & $\mathrm{Q}_{\mathrm{C}}$ \\
\hline Moped, Unpedaled Gas & $117.0^{g}$ & 1.23 & 70 & 0.97 & 0.099 & 20.0 & 8.9 & 0.88 & $\mathrm{Q}_{\mathrm{E}}^{*}$ \\
\hline Segway $\mathrm{I}^{\mathrm{TM}}$ & 181.9 & 2.20 & 70 & 1.51 & $0.154^{\mathrm{h}, \mathrm{i}}$ & $12.5^{\mathrm{i}}$ & 5.6 & 0.86 & $\mathrm{Q}_{\mathrm{E}}$ \\
\hline Auto, Prius Hybrid Hwy & $45.0^{j}$ & 0.47 & 70 & 0.37 & 0.038 & $48.0^{\mathrm{j}}$ & 21.5 & 0.82 & $\mathrm{Q}_{\mathrm{C}}$ \\
\hline Electric Car, Tesla Hwy & 36.6 & 0.44 & 70 & 0.30 & $0.031^{\mathrm{h}, \mathrm{k}}$ & $48.0^{\mathrm{k}}$ & 21.5 & 0.66 & $\mathrm{Q}_{\mathrm{C}}$ \\
\hline Auto, Civic Nonhybrid Hwy & $36.0^{j}$ & 0.38 & 70 & 0.30 & 0.030 & $48.0^{\mathrm{j}}$ & 21.5 & 0.65 & $\mathrm{Q}_{\mathrm{C}}$ \\
\hline Human Walking & 413.3 & & 70 & 3.43 & $0.350^{1}$ & 4.0 & 1.8 & 0.63 & $\mathrm{Q}_{\mathrm{E}}{ }^{*}$ \\
\hline Auto, Prius Hybrid City & $48.0^{\mathrm{j}}$ & 0.51 & 70 & 0.40 & 0.041 & $20.0^{\mathrm{j}}$ & 8.9 & 0.37 & $\mathrm{Q}_{\mathrm{E}}$ \\
\hline SUV, Escalade Hwy & $18.0^{\mathrm{j}}$ & 0.19 & 70 & 0.15 & 0.015 & $48.0^{\mathrm{j}}$ & 21.5 & 0.33 & $\mathrm{Q}_{\mathrm{C}}$ \\
\hline Electric Car, Tesla City & 39.0 & 0.47 & 70 & 0.32 & $0.033^{\mathrm{h}, \mathrm{k}}$ & $20.0^{\mathrm{k}}$ & 8.9 & 0.30 & $\mathrm{Q}_{\mathrm{E}}$ \\
\hline Auto, Civic Nonhybrid City & $25.0^{j}$ & 0.26 & 70 & 0.21 & 0.021 & $20.0^{j}$ & 8.9 & 0.19 & $\mathrm{Q}_{\mathrm{E}}$ \\
\hline SUV, Escalade City & $12.0^{\mathrm{j}}$ & 0.12 & 70 & 0.10 & 0.010 & $20.0^{\mathrm{j}}$ & 8.9 & 0.09 & $\mathrm{Q}_{\mathrm{E}}$ \\
\hline Airplane, 2 Person N99VE & $101.6^{\mathrm{d}}$ & 1.07 & 140 & 0.84 & 0.086 & $169.5^{\mathrm{d}}$ & 75.8 & 6.52 & $\mathrm{Q}_{\mathrm{E}}$ \\
\hline Auto, Civic 2 Person & $25.0^{\mathrm{j}}$ & 0.52 & 140 & 0.41 & 0.042 & $20.0^{\mathrm{j}}$ & 8.9 & 0.38 & $\mathrm{Q}_{\mathrm{E}}$ \\
\hline Auto, Prius 4 Person Hwy & $45.0^{\mathrm{j}}$ & 1.89 & 280 & 1.49 & 0.152 & $48.0^{\mathrm{j}}$ & 21.5 & 3.27 & $\mathrm{Q}_{\mathrm{C}}$ \\
\hline Auto, Prius 4 Person City & $48.0^{j}$ & 2.02 & 280 & 1.59 & 0.163 & $20.0^{\mathrm{j}}$ & 8.9 & 1.45 & $\mathrm{Q}_{\mathrm{E}}$ \\
\hline Bus, Avg Load Urban & 29.5 & 0.31 & 609 & 0.25 & $0.025^{\mathrm{m}}$ & 17.0 & 7.6 & 0.19 & $\mathrm{Q}_{\mathrm{E}}^{*}$ \\
\hline Spacecraft, Voyager 1 & $7.3 \mathrm{E}+06$ & & $7.2 \mathrm{E}+02^{\circ}$ & $6.1 \mathrm{E}+04$ & $6.2 \mathrm{E}+03^{\mathrm{n}, \mathrm{o}, \mathrm{p}}$ & $3.8 \mathrm{E}+04$ & $1.7 \mathrm{E}+04^{\circ}$ & $1.0 \mathrm{E}+08$ & $\mathrm{Q}_{\mathrm{E}}$ \\
\hline Train, Avg Load Amtrak & 46.1 & 0.48 & $1.26 \mathrm{E}+03$ & 0.38 & $0.039^{\mathrm{m}}$ & 45.0 & 20.1 & 0.78 & $\mathrm{Q}_{\mathrm{E}}{ }^{*}$ \\
\hline Train, Avg Load Commuter & 48.4 & 0.51 & $1.57 \mathrm{E}+03$ & 0.40 & $0.041^{\mathrm{m}}$ & 35.0 & 15.6 & 0.64 & $\mathrm{Q}_{\mathrm{E}}{ }^{*}$ \\
\hline Bus, Full Urban & 74.4 & 0.78 & $2.52 \mathrm{E}+03$ & 0.62 & $0.063^{1}$ & 17.0 & 7.6 & 0.48 & $\mathrm{Q}_{\mathrm{E}}^{*}$ \\
\hline Airliner, Avg Passenger & 33.1 & 0.35 & $6.30 \mathrm{E}+03$ & 0.27 & $0.028^{1}$ & 270.0 & 120.7 & 3.38 & $\mathrm{Q}_{\mathrm{E}}{ }^{*}$ \\
\hline Airliner, Avg Passenger 2006 & 63.8 & 0.67 & $6.85 \mathrm{E}+03^{q, v}$ & 0.53 & $0.054^{q, r}$ & $93.0^{\mathrm{s}, \mathrm{t}}$ & 41.6 & 2.24 & $\mathrm{Q}_{\mathrm{E}}$ \\
\hline Truck, Avg Intercity & 778.2 & 8.17 & $1.32 \mathrm{E}+04$ & 6.46 & $0.659^{\mathrm{u}}$ & 65.0 & 29.1 & 19.14 & $\mathrm{Q}^{*}$ \\
\hline Train, High Speed Full Load & 602.2 & 7.29 & $1.40 \mathrm{E}+04$ & $5.00^{\mathrm{f}}$ & 0.510 & 110.0 & $49.2^{\mathrm{f}}$ & 25.09 & $\mathrm{Q}_{\mathrm{C}}$ \\
\hline Train, Full Load Intercity & 140.5 & 1.70 & $1.75 \mathrm{E}+04$ & 1.17 & $0.119^{1}$ & 45.0 & 20.1 & 2.39 & $\mathrm{Q}_{\mathrm{E}}^{*}$ \\
\hline Airship, 1936 & 224.4 & 2.36 & $2.27 \mathrm{E}+04^{\mathrm{w}}$ & 1.86 & $0.190^{\mathrm{w}}$ & $66.0^{\mathrm{w}}$ & 29.5 & 5.60 & $\mathrm{Q}_{\mathrm{C}}$ \\
\hline Truck, Best & 2530.6 & 26.57 & $3.64 \mathrm{E}+04$ & $21.00^{\mathrm{f}}$ & 2.143 & 55.0 & $24.6^{\mathrm{f}}$ & 52.68 & $\mathrm{Q}_{\mathrm{C}}$ \\
\hline Airliner 747-8, 467 Pass. & 116.9 & 1.23 & $4.46 \mathrm{E}+04$ & 0.97 & $0.099^{\mathrm{x}, \mathrm{y}, \#}$ & $650.0^{\mathrm{x}}$ & 290.5 & 28.76 & $\mathrm{Q}_{\mathrm{C}}$ \\
\hline Airliner, 747-200-CCW Freight & 361.3 & 3.79 & $1.33 \mathrm{E}+05$ & $3.00^{\mathrm{f}}$ & 0.306 & 580.0 & $259.2^{\mathrm{f}}$ & 79.37 & $\mathrm{Q}_{\mathrm{C}}$ \\
\hline Airliner, $747-8,10 \mathrm{lb} / \mathrm{ft} 3$ Freight & 305.8 & 3.21 & $1.33 \mathrm{E}+05$ & 2.54 & $0.259^{\mathrm{x}, \mathrm{y}, \#}$ & $650.0^{x}$ & 290.5 & 75.24 & $\mathrm{Q}_{\mathrm{C}}$ \\
\hline Train, Avg Freight & 2479.8 & 26.04 & $4.00 \mathrm{E}+06$ & 20.59 & $2.100^{\mathrm{u}}$ & 60.0 & 26.8 & 56.32 & $\mathrm{Q}_{\mathrm{E}}{ }^{*}$ \\
\hline Train, Dense Freight (Coal) & 4416.4 & 46.37 & $8.30 \mathrm{E}+06$ & 36.68 & $3.740^{\mathrm{u}}$ & 60.0 & 26.8 & 100.29 & $\mathrm{Q}_{\mathrm{E}}^{*}$ \\
\hline
\end{tabular}


(Table 1) contd.....

\begin{tabular}{|c|c|c|c|c|c|c|c|c|c|}
\hline \multirow[b]{2}{*}{ Mode } & Fuel Econ. & Emissive Eff. & Payload Mass & \multirow[b]{2}{*}{$1 / \varepsilon_{F}$} & $1 / \varepsilon_{Q}$ & Speed & Speed & $\mathbf{Q}$ & \multirow[b]{2}{*}{ Form } \\
\hline & (Person-MPG) & $(\mathrm{kg}-\mathrm{km} / \mathrm{gCO} 2 \mathrm{e})$ & (kg) & & $\begin{array}{c}\text { (kg- } \\
\text { m/Jth) }\end{array}$ & (Mi/Hr) & $(\mathbf{m} / \mathbf{s})$ & (s) & \\
\hline Pipeline, 6 Inch Crude Oil & 2964.0 & 31.12 & $2.00 \mathrm{E}+07^{\mathrm{z}}$ & 24.61 & $2.510^{z}$ & 7.4 & 3.3 & 8.26 & $\mathrm{Q}_{\mathrm{C}} *$ \\
\hline Tanker, Valdez to Long Beach & 20192.7 & 212.01 & $1.20 \mathrm{E}+08^{\mathrm{z}}$ & 167.69 & $17.100^{\mathrm{z}}$ & $18.4^{z}$ & 8.2 & 140.63 & $\mathrm{Q}_{\mathrm{C}}$ \\
\hline Tanker, VLCC Class & 15664.1 & 164.46 & $2.00 \mathrm{E}+08$ & $130.00^{\mathrm{f}}$ & 13.265 & 18.0 & $8.0^{\mathrm{f}}$ & 106.70 & $\mathrm{Q}_{\mathrm{C}}$ \\
\hline Tanker, ULCC Class & 38558.5 & 404.84 & $3.20 \mathrm{E}+08$ & $320.00^{f}$ & 32.653 & 20.0 & $8.9^{\mathrm{f}}$ & 291.90 & $\mathrm{Q}_{\mathrm{C}}$ \\
\hline Oil, Prudhoe Bay to Long Beach & 12517.1 & 131.42 & $4.16 \mathrm{E}+08^{\mathrm{z}}$ & 103.95 & $10.600^{z}$ & $15.4^{z}$ & 6.9 & 73.14 & $\mathrm{Q}_{\mathrm{C}}$ \\
\hline Pipeline, 40 Inch Crude Oil & 9069.0 & 95.22 & $8.87 \mathrm{E}+08^{\mathrm{z}}$ & 75.32 & $7.680^{2}$ & 7.4 & 3.3 & 25.27 & $\mathrm{Q}_{\mathrm{C}} *$ \\
\hline Pipeline, 48 Inch Trans Alaska & 5833.4 & 61.25 & $1.30 \mathrm{E}+09^{\mathrm{z}}$ & 48.44 & $4.940^{z}$ & $7.4^{\mathrm{z}}$ & 3.3 & 16.25 & $\mathrm{Q}_{\mathrm{C}}$ \\
\hline
\end{tabular}

${ }^{a}$ Weaver, M. Fastest Human Pure Muscle Speeds Illustrated. http://www.speed101.com/sprint/2001sprints.htm. (accessed Aug 28, 2007). ${ }^{b}[11] .{ }^{c}$ Vetter, C. 1985 Craig Vetter Fuel Economy Contest. http://www.craigvetter.com/pages/470MPG/470MPG\%20Main.htm. (accessed Oct 17, 2007). 'Seeley, B. The World‘s Most Efficient Aircraft! 1994. http://www.cafefoundation.org/v2/pdf apr/WMEA.pdf. (accessed Nov 1, 2007). ${ }^{\mathrm{e}}$ Twike, 2007 Twike Specifications. http://www.twike.com/twike con.htm. (accessed Jan 1, 2008). ${ }^{f}[3] .{ }^{g}$ Verucci Gas Scooters. 2007 Gekgo Worldwide. http://www.gekgo.com/verucci-gas-scooters.htm. (accessed Sep 27, 2007). ${ }^{h}[14]$. ${ }^{\mathrm{i}}[15]$. ${ }^{\mathrm{j}}$ US Department of Energy. MPG Ratings, 2007 Model Year. http://www.fueleconomy.govfeg/fe_test_schedules.shtml. (accessed Dec 29, 2007). ${ }^{k}$ Simpson, A. Where the Rubber Meets the Road. http://www.teslamotors.com/blog4/?p=60. (accessed Oct 19, 2007). ${ }^{1}[9] .{ }^{\mathrm{m}}$ Davis, S.; Diegel, S. Transportation Energy Data Book: Edition 26. ORNL-6978. http://cta.ornl.gov/data/index.shtml. (accessed Dec 8, 2007). ${ }^{\text {n}}[8] .{ }^{\circ}$ NASA. Voyager Weekly Report. http://www.voyager.jpl.nasa.gov/mission/weekly-reports/index.htm. (accessed Aug 28, 2007). ${ }^{\mathrm{p}}$ Wade, M. Titan 3E Specifications. http://www.astronautix.com/lvs/titan3e.htm. (accessed Aug 28, 2007). ${ }^{\mathrm{q}}$ US Bureau of Transportation Statistics. Domestic Flight Availability and Distance, 2004. http://www.bts.gov/publications/white_house_economic_statistics_briefing_room/january_2004/html/domestic_flight_availability_and_distance. htm. (accessed Nov 1, 2007). ${ }^{\mathrm{r}}$ Air Transport Association. Fuel Efficiency: US Airlines, 2007. http://www.airlines.org/economics/energy/fuel+efficiency.htm. (accessed Nov 1, 2007). ${ }^{s}$ Fallows, J. Freedom of the Skies. http://www.theatlantic.com/doc/200106/fallows. (accessed Oct 19, 2007). 'Holmes, B. Life After Airliners_VII, Slide 25, 2004. http://www.airtraveler.com/Airtraveler/NASA/Bruce/default.aspx. (accessed Nov 3, 2007). "US Congressional Budget Office. Energy Use in Transportation, 1982, http://www.cbo.gov/ftpdocs/53xx/doc5330/doc02b-Entire.pdf, Table 1. (accessed Dec 1, 2007). ${ }^{v}$ Airline Industry Information. New Regulations Result in Increased Average Weight of Passengers and Luggage on US Airlines. http://findarticles.com/p/articles/mi_m0CWU/is_2005_August_12/ai n14892484. (accessed Nov 1, 2007). wick, H. The Golden Age of Passenger Airships: Graf Zeppelin and Hindenburg. Washington, DC: Smithsonian Institution Press, 1985, pp. 111-123. ${ }^{\times}$Boeing Corporation. Preliminary 747-8 Airport Compatibility. http://www.boeing.com/commercial/airports/acaps/7478brochure.pdf. (accessed Nov 1, 2007). ${ }^{\mathrm{y}}$ Elert, G. The Physics Factbook. Energy Density of Aviation Fuel. http://hypertextbook.com/facts/2003/EvelynGofman.shtm. (accessed Nov 1, 2007). ${ }^{\mathrm{z}}$ Maxim, L. Trans Alaska Pipeline System Renewal Environmental Impact Statement: 4.9 Energy

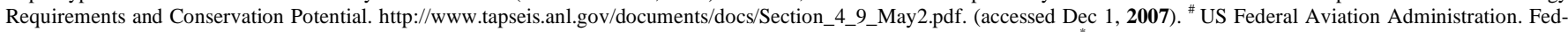
eral Aviation Regulation 121.645. http://www.flightsimaviation.com/data/FARS/part_121-645.htm. (accessed Nov 4, 2007). "From estimated speed.

charger energy input, the battery charge, storage, and discharge efficiencies are accounted for. Electrical powerline transmission efficiency was assumed to be $96 \%$. Net efficiency of the generating facility at the other end of the powerline is typically 33\% (El-Wakil [14]). The range of the prototype Neodymics Cyclemotor electric bicycle is 17.7 kilometers at 11.2 meters per second. Fully charging the four DeWalt lithium iron phosphate battery packs (model DC9360) required 360 Watt-hours of electrical energy fed into the battery chargers. So, one may travel 17.7 kilometers on an electric bicycle using 4.1 megajoules of thermal energy released at a typical electrical powerplant.

In a similar manner, efficiency of the Segway ${ }^{\mathrm{TM}} \mathrm{I} 2^{\mathrm{TM}}$ personal transporter was determined from the manufacturer's specifications (Segway [15]). This device uses the same battery chemistry as the Neodymics Cyclemotor, so battery efficiency was assumed to be the same. It is suspected that much of the energy consumed by the $\mathrm{I} 2^{\mathrm{TM}}$ is used to keep it upright.

Fig. (3) also compares efficiency in the movement of petroleum and people. Most petroleum is transported by ship or pipeline. These means are about 1000 times more efficient than a single occupant SUV.

\section{DISCUSSION}

This analysis shows that light personal vehicles perform far better than heavy ones. Energy used to produce vehicles and transportation infrastructure was not considered here, and such an analysis would make light vehicles appear even more attractive. For all payload weight classes, the payload to vehicle mass ratio of the best performers is between three and four. Since most people tend to travel individually when possible, and energy resources are becoming increasingly scarce with respect to demand, it would appear that personal vehicles of the future will be very light by today's standards. A challenge in the development of urban transportation infrastructure will be to allow for safe use of these personal vehicles amidst heavier cargo and mass transit vehicles. There is a related challenge to improving efficiency ratings for personal vehicles in developed countries. Here, people tend to view a light vehicle as impractical because of it lacks the crumple zone they have become accustomed to. A light personal vehicle such as a bicycle is often seen as an exercise toy to be carried on top of a car. Future changes in environmental and economic considerations may induce a sea change in this attitude.

Energetic performance was determined for widely different modes of transportation. Streamlined human powered vehicles excel in personal vehicle energetic performance because of the relatively efficient human engine and the designer's careful attention to aerodynamics. Commercial airliners also perform well because people are willing to crowd themselves into an aerodynamically optimized fuselage for fast, long distance travel. By terrestrial standards, a one-way trip into the void of interstellar space can be extremely fast and efficient. Using the chemical energy release of the launch vehicle, and the present displacement from earth, $Q_{E}$ for the Voyager 1 spacecraft is on the order of $10^{8}$ seconds. The gravitational assist in propelling Voyager 1 is acknowledged as free, since it was not paid for with chemical combustion. Solar energy captured by various means and used 
Energetic Performance (seconds): Read at intersection of each diagonal with the horizontal blue line

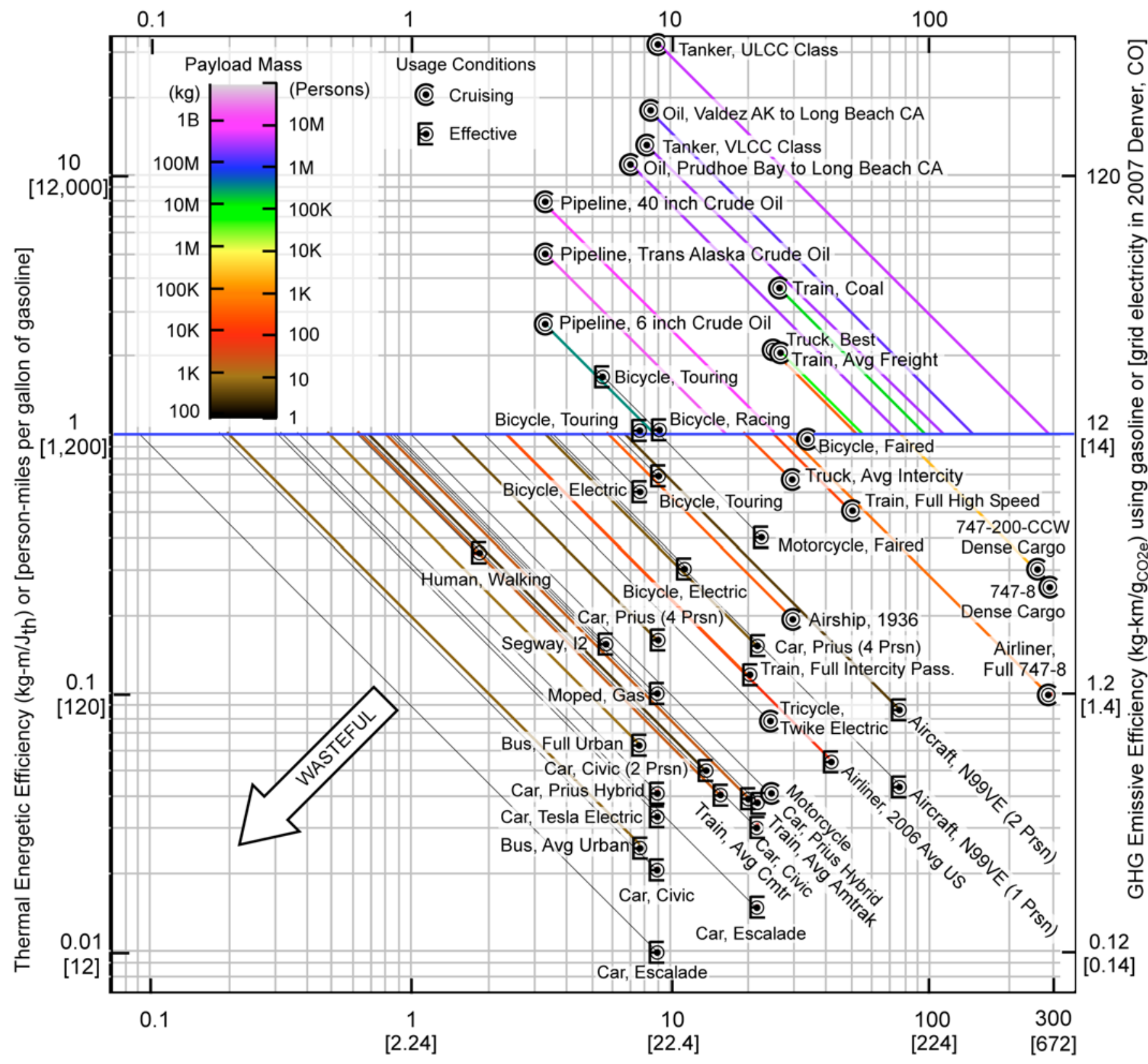

Average Speed (meters per second) or [miles per hour]

Fig. (3). Transportation matrix indicating thermal energetic efficiency $\left(\boldsymbol{\varepsilon}_{Q}^{-1}\right)$ and energetic performance $(Q)$ for various modes at typical loads and usage speeds. Since $Q$ is the product of thermal efficiency and speed, it is read by following the diagonal (constant $Q$ ) lines to the point where thermal efficiency is unity. Effective values for mass transit take wait time into account and are strongly influenced by utilization, delays and terminal pedestrian flow. Steady state cruising conditions are denoted by "C" data point icons. Average conditions which include velocity changes in crowded environments are represented by "E" icons. The price for convenience of personal transit is evident when compared to mass transit.

for earthly transport without terrestrial combustion is, in a similar sense, free.

\section{ACKNOWLEDGEMENTS}

The author gratefully acknowledges receiving encouragement, helpful comments or suggestions from A. Babson and Dr. D. Faber; graphics review from D. Bahr, Dr. W. Connors, L. Dore, H. Noeldner, P. Nonn, Dr. G. Penn and Dr. C. Sprott; mathematical review from T. Schmidt and J. Snyder; and data refinement from R. Finley, G. Hertzler, T. Millett, R. Parker, Dr. R. Steeves, M. Weaver, C. Vetter and R. Zitarosa.

\section{APPENDIX: INTEGRAL DEFINITION OF EFFEC- TIVE ENERGETIC PERFORMANCE}

The effective (or time averaged) speed $V_{E}$ is defined by the integral of the path length $d l$ divided by the elapsed time $T$. 


$$
\begin{aligned}
V_{E} & =\left(\int_{0}^{T} v d t\right) / T=\left(\int_{0}^{T}(d l / d t) d t\right) / T \\
V_{E} & =\left(\int_{0}^{T} d l\right) / T
\end{aligned}
$$

Substituting into $\mathrm{Eq} 7$ and solving for $Q$, we obtain:

$$
\begin{aligned}
& Q_{E}=\left(M_{P}\left(l_{T}-l_{0}\right)\left(\int_{0}^{T} d l\right) / T\right) /\left(\int_{0}^{T} d E\right) \\
& Q_{E}=M_{P} l V_{E} / E_{t h}
\end{aligned}
$$

Dividing numerator and denominator by elapsed time, we obtain the differential form:

$$
\begin{aligned}
Q_{E} & =\left(M_{P}\left(\left(\int_{0}^{T} d l\right) / T\right)^{2}\right) /\left(\left(\int_{0}^{T} d E\right) / T\right) \\
Q_{E} & =M_{P} V_{E}^{2} /\left\langle P_{t h}\right\rangle
\end{aligned}
$$

But the exact time averaged payload kinetic energy is:

$$
<E_{k}>=M_{P} V_{r m s}^{2} / 2
$$

where $V_{r m s}$ is the root mean square velocity:

$$
V_{r m s}^{2}=\left(\int_{0}^{T} v^{2} d t\right) / T
$$

The root mean square velocity may also be defined statistically for any time dependent speed profile by using the standard deviation, $\sigma_{V}$.

$V_{r m s}^{2}=V_{E}^{2}+\sigma_{V}^{2}$

By both definitions, we see that the minimum root mean square velocity for any time dependent velocity profile is the effective speed, and that these two quantities are equal when velocity is constant over time.
$V_{r m s}^{2} \geq V_{E}^{2}$

It follows that the minimum average payload kinetic energy for transport at the same effective speed becomes:

$\left\langle E_{k}\right\rangle_{\min }=M_{P} V_{E}^{2} / 2$

Effective energetic performance becomes the following ratio:

$Q_{E}=2\left\langle E_{k}\right\rangle_{\text {min }} /\left\langle P_{t h}\right\rangle$

\section{REFERENCES}

[1] Gabrielli, G.; von Karman, T. Mech. Eng., 1950, 72, 775-781.

[2] Stamper, J. Aeronaut. J., 1975, 79, 169-178.

[3] Teitler, S.; Proodian, R. J. Energy, 1980, 4, 46-48.

[4] Greenewalt, C. Proc. Am. Philos. Soc., 1977, 121, 100-106.

[5] Carson, B. J. Aircr., 1982, 19, 473-479.

[6] Minetti, A.; Pinkerton, J.;Zamparo, P. Proc. R. Soc. Lond. B, 268, 2001, 1351-1360.

[7] Young, J.; Smith, R.; Hillmansen, S. Ingenia, 2005, 22, 46-51.

[8] Sutton, G. Rocket Propulsion Elements. John Wiley and Sons: New York. 1986, pp. 21-34

[9] Hobson, A. Phys. Educ., 2003, 38, 109-114.

[10] US Department of Energy, MPG Ratings, 2007 Model Year. http:// www.fueleconomy.govfeg/fe_test_schedules.shtml. (accessed Dec 29, 2007).

[11] DeLong, F. DeLong's Guide to Bicycles and Bicycling. Chilton Book Company: Radnor Pennsylvania. 1974, pp. 186-192.

[12] Google RechargeIT.org, Vehicle Calculator. http://www.google. org/recharge/dashboard/calculator\#notes. (accessed Oct 19, 2007).

[13] City of Denver, 2007 Climate Action Plan. http://www.greenprintdenver.org/docs/Greenprint_Council_Report.pdf. (accessed Oct 19, 2007).

[14] El-Wakil, M. Powerplant Technology. McGraw-Hill: New York. 1984, pp. 30-78.

[15] Segway, Inc., Segway I2 Specifications. http://www.segway.com/ downloads/pdfs/i2-specs.pdf. (accessed Oct 19, 2007). 